\title{
Preservação arquitetônica: teoria, legislação e prática
}

Isis Salviano Roverso Soares*

Claudia Terezinha de Andrade Oliveira**

\section{Resumo}

No campo do restauro, a palavra preservação compreende desde a intenção de salvaguardar o monumento arquitetônico, passa pelos estudos e análises específicos do campo disciplinar, até encontrar-se com as ações práticas da intervenção em monumentos históricos. Ou seja, a preservação carrega os significados próprios da teoria do restauro e caminha para as ações práticas nas mais diversas escalas.

A falta de diálogo entre as ações práticas e a teoria do restauro leva o patrimônio arquitetônico a uma situação de risco: de um lado, faltam ações de manutenção preventiva. De outro, as intervenções realizadas, por vezes, estão desprovidas de estrutura teórica própria do campo disciplinar do restauro.

É necessário facilitar o caminho entre a teoria e a prática. Para tanto, algumas iniciativas são bem-vindas, dentre elas, a disseminação da cultura da preservação e o esclarecimento sobre os conceitos próprios da área, inclusive seu significado.

A transição entre a teoria e a prática da preservação seria facilitada, se fosse possível contar com uma legislação coerente com os fundamentos do campo disciplinar do restauro.

Um exemplo desse descompasso entre a teoria e a prática da preservação é a forma tradicional de apresentação gráfica dos sistemas prediais, que não contempla as situações de conflito existentes, ou seja, nos desenhos em planta não é possível verificar as interferências tridimensionais, o que leva a uma simplificação das soluções. Como resultado, no momento de execução das obras, diversos imprevistos surgem, algo que poderia ser identificado nos levantamentos cadastrais e documentação da obra.

Para discutir essa questão, selecionamos o projeto de instalações elétricas do edifício Vila Penteado, apresentamos a situação existente e os desdobramentos do projeto revisado.

Palavras-chave: Preservação arquitetônica. Manutenção. Vila Penteado. 


\title{
Architecture preservation: theory, law and practice
}

\begin{abstract}
In the restoration field, the preservation word comprises since the intention of safeguard the architectural monument, passing through specific studies, and analyzes of the disciplinary field, until to meet with the practical actions interventions in the historical monuments. That means, the preservation includes the own meaning of the restoration theory and goes to the practical actions into the most variable scales.

The dialogue lack between the practical actions and the restoration theory goes the architectural heritage to a risk situation: in on one side missing preventive maintenance actions, on the other the interventions done, sometimes, are devoid of own theoretical structure of restoration disciplinary field.

It is necessary to smooth the way between theory and practice. For this, some initiatives are welcome, among them the spread of the preservation culture and the clarification on the own preservations concepts of the area, including its meaning.

The transition between the theory and the preservation practice would be facilitated if were possible to have a legislation coherent with the restoration disciplinary field fundamentals. An example of the gap between theory and the preservation is the traditional graphic presentation of the building systems, which does not address the existents conflict situation, it means, in the building maps is not possible to verify the three-dimensional interferences which goes to a simplified solution. The result, at the time of execution of works, many contingencies arise, something that could be identified in the cadastral survey and documentation of the work.

To discuss this issue, we selected the electrical installation project of the Vila Penteado building, presenting, the actual situation and the development of the revised project.
\end{abstract}

Key words: Architecture preservation. Maintenance. Vila Penteado. 


\section{Introdução}

A palavra preservação possui amplo significado, dentro das diversas áreas do conhecimento, e normalmente está relacionada ao cuidado e à salvaguarda do patrimônio. No campo do restauro, a palavra preservação compreende desde a intenção de salvaguardar o monumento arquitetônico, passa pelos estudos e análises específicos do campo disciplinar, até encontrar-se com as ações práticas da intervenção em monumentos históricos. Ou seja, a preservação carrega os significados próprios da teoria do restauro e caminha para as ações práticas, desde as manutenções simples e ordinárias, até as intervenções de escala abrangente.

Entretanto é verificável que as ações práticas que vêm sendo executadas em bens patrimoniais, no Brasil e no exterior, nem sempre estão munidas de toda a bagagem intrínseca ao termo.

A falta de diálogo entre as ações práticas e a teoria do restauro leva o patrimônio arquitetônico a uma situação de risco: de um lado, faltam ações de manutenção preventiva. De outro, as intervenções realizadas, por vezes, estão desprovidas de estrutura teórica própria do campo disciplinar do restauro. Como bem expõe Kühl (2009, p. 220):

É possível verificar, em intervenções ou propostas de atuação em bens de interesse histórico e artístico, a falta de fundamentos culturais. Enorme contradição, pois, por um lado, esses edifícios são escolhidos por serem "bens culturais", como forma também de valorizar a imagem de uma instituição ou de legitimar uma dada iniciativa; por outro lado, são os aspectos histórico-artísticos, memoriais e simbólicos da edificação que passam ao largo das questões projetuais. Ou seja, esses exemplares são eleitos por terem interesse histórico, mas as intervenções desprezam os valores culturais que motivaram sua tutela. Prevalecem questões funcionais - com uma destinação predeterminada que orienta a intervenção -, ou ainda políticas, midiáticas e de exploração visando lucros.

As ações projetuais devem ser construídas sobre um embasamento teórico consistente, que resgate as características singulares da obra e ainda estabeleça as condições práticas da intervenção. Em muitos casos, os projetos de intervenção no patrimônio histórico brasileiro revelam a falta desse alicerce teórico, e, nos raros casos onde há a reflexão teórica, essa não atinge as ações práticas das restaurações. Tirello (1999, p. 202 
) apresenta esse quadro, no depoimento "Redescobrindo e Restaurando as Pinturas Murais dos Edifícios da USP":

[...] devido à pouca tradição na conservação do patrimônio histórico cultural, no Brasil, as restaurações de edifícios e obras de arte, frequentemente, se caracterizam pela improvisação, e, o que é pior, costumam ser promovidas quando esses bens já se encontram em avançado estado de degradação. No caso dos edifícios, a situação se agrava. As intervenções quase sempre se reduzem às "reformas" emergenciais que priorizam as consolidações estruturais deixando fora do projeto a restauração dos metais, dos estuques, das madeiras e pinturas antigas originais. Os elementos componentes dessas arquiteturas, que distinguem e caracterizam os estilos, quando danificados, costumam, nesse tipo de intervenção assistemática, ser substituídos por modelos "similares", que terminam por transformar o edifício em um híbrido arquitetônico, distanciado de sua própria história e natureza. São ações que ao longo dos anos vêm contribuindo para a descaracterização de muitos prédios históricos de São Paulo, construídos no final do século XIX e início do século XX.

Entretanto qual é a origem dessa desarticulação entre a conceituação teórica e as ações de intervenção? Em que medida os profissionais teóricos enfrentam os problemas práticos, ou, ainda, com que frequência é possível contar com esses profissionais, durante o desenvolvimento dos projetos e ainda no período das obras? E aqui a questão a se trabalhar não está relacionada à disponibilidade dos mesmos, e sim ao fator que impulsiona a contratação de teóricos para o acompanhamento das fases de desenvolvimento do projeto e execução da obra, sabendo que os mesmos são imprescindíveis para a correta aplicação dos conceitos. E, ainda, considerando que os fatores econômicos não devem se tornar impeditivos para a contratação e acompanhamento das obras por parte dos profissionais teóricos, em que medida os conceitos, tão bem formatados em textos e discursos, tornam-se aplicáveis?

Por outro lado, quais são os desafios dos profissionais que viabilizam a obra? Qual é o entendimento teórico desses profissionais, visando sua tradução para as ações de intervenção? E em que medida não apenas os dirigentes das obras, como também os trabalhadores da construção civil estão capacitados a manipular exemplares históricos ou, ao menos, compreendem a importância do patrimônio em que estão trabalhando? 


\section{A questão da preservação}

É necessário facilitar o caminho entre a teoria e a prática. Para tanto, algumas iniciativas são bem-vindas, dentre elas, a disseminação da cultura e o esclarecimento sobre os conceitos próprios da preservação, inclusive seu significado.

Alimentando o entendimento sobre preservação, conservação e restauro, é possível obter esclarecimentos precisos no texto "Restauração hoje: método, projeto e criatividade", de Beatriz Kühl (2007, pp. 19-34), baseado na Carta de Veneza. Preservação, no Brasil, é o termo mais abrangente, que abarca métodos e procedimentos de intervenção nos bens, incluindo a manutenção, a conservação e a restauração. Já a manutenção designa as ações cotidianas e periódicas que têm por objetivo resolver os problemas assim que surgem. Na manutenção, é importante trabalhar por analogia, optando por formas e materiais iguais ou semelhantes aos originais. A conservação implica manutenção permanente e objetiva, manter o estado existente do monumento histórico(1). Já a restauração adquire um caráter excepcional, designando intervenção de maior envergadura, em que se deve operar através da distinguibilidade.

O campo disciplinar do restauro tem por objetivo estudar a preservação de bens culturais, com métodos e referenciais teóricos próprios. Esses estudos trazem implicações práticas, que vão desde a documentação do patrimônio, até a execução de intervenções planejadas, segundo critérios e requisitos específicos do campo disciplinar, aplicadas às especificidades do patrimônio estudado. Esse trabalho de análise requer reflexão crítica, interdisciplinaridade e criatividade projetual. Entretanto, desde os estudos do monumento histórico até a efetivação das ações de intervenção, diversos obstáculos surgem. Um desses obstáculos refere-se ao conteúdo e à organização da legislação vigente no Brasil.

A transição entre a teoria e a prática da preservação seria facilitada, se fosse possível contar com uma legislação coerente com os fundamentos do campo disciplinar do restauro. Dessa forma, o esclarecimento sobre a teoria da preservação poderia atingir toda pessoa interessada no assunto, evitando julgamentos enganosos.

Um exemplo dessa incoerência é a Lei n. 11.228, de 25 de junho de 1992, Código de Obras e Edificações do Município de São Paulo, que contém as informações gerais e específicas para orientação dos projetos da cidade de São Paulo. Essa lei é recente, se 
comparada à Carta de Veneza, documento-base do Icomos(2), fruto do congresso realizado em 1964, e ainda em vigor. Embora tenha sido aprovada quase três décadas após a publicação da Carta de Veneza, a Lei n. 11.228 carrega conceitos contrários à Carta, o que resulta em equívocos por parte dos profissionais que a consultam, sem o conhecimento e entendimento dos princípios essenciais do campo do restauro.

A Lei n. 11.228 traz a seguinte definição de restauro: "RESTAURO OU RESTAURAÇÃO: recuperação de edificação tombada ou preservada, de modo a restituir-lhe as características originais"(3).

Lembremos que não há, no Código de Obras, indicação de excepcionalidade para obras preservadas, ou seja, apesar de haver legislação e órgãos específicos que definem os limites de possíveis intervenções e ainda fiscalizam as obras em monumentos históricos, a Lei n. 11.228 é válida para qualquer imóvel pertencente ao Município de São Paulo:

Art. $1^{\circ}$. - Fica aprovado o Código de Obras e Edificações, que dispõe sobre as regras gerais e específicas a serem obedecidas no projeto, licenciamento, execução, manutenção e utilização das obras e edificações, dentro dos limites dos imóveis, no Município de São Paulo.(4)

$E$ os equívocos são reproduzidos por órgãos e instituições regionais vinculadas à construção civil. Diversos exemplos poderiam ser apontados, dentre eles, destaca-se o conceito de restauração divulgado pela regional de Bauru do Crea-SP:

O que é restauração? A restauração é um conjunto de atividades que visa a restabelecer o estado original ou próximo deste e anterior aos danos decorrentes da ação do tempo, ou do próprio homem em intervenções que descaracterizam um bem imóvel ou móvel. A restauração visa a garantir a permanência de um testemunho físico e real de época passada para gerações futuras. Os processos de restauração são orientados por posturas consolidadas em cartas patrimoniais.(5)

A definição de restauração apresentada nesses documentos nega a validade das transformações ocorridas na obra pela passagem do tempo e define um período histórico como mais relevante do que outro. Ainda afirma que os processos de restauração são orientados pelas cartas patrimoniais, sem levar em consideração que as cartas não formam um conjunto homogêneo e coerente de documentos. 
As cartas patrimoniais são fruto da discussão em um determinado momento e têm um papel claro, que é indicativo, oferecendo orientações gerais. Sua importância é indiscutível, mas, dentre as várias cartas, há inclusive incoerências e até contradições. É de suma importância entender o período histórico e as circunstâncias que levaram à redação das cartas, e só então entender que elas não podem e não devem ser colocadas em um mesmo plano. As cartas não devem ser usadas para justificar ações, elas devem orientar a reflexão teórica e crítica que propicie o debate dos aspectos teóricometodológicos e técnico-operacionais da restauração, a fim de que os projetos de preservação sejam munidos de seu princípio imutável, que é a salvaguarda do monumento histórico.

A Carta de Veneza (1964) esclarece o conceito de restauração:

Art. $9^{\circ}$. A restauração é uma operação que deve ter caráter excepcional. Tem por objetivo conservar e revelar os valores estéticos e históricos do monumento e fundamenta-se no respeito ao material original e aos documentos autênticos. Termina onde começa a hipótese; no plano das reconstituições conjeturais, todo trabalho complementar reconhecido como indispensável por razões estéticas ou técnicas destacar-se-á da composição arquitetônica e deverá ostentar a marca do nosso tempo. A restauração será sempre precedida e acompanhada de um estudo arqueológico e histórico do monumento.

É necessário ressaltar os valores estéticos e históricos da matéria como transformada pelo tempo, não apenas a referência ao material original, como também as alterações provocadas pelo tempo nesse material. O limite da restauração deve estar contido antes do início da hipótese, ou seja, não cabem suposições em substituição à documentação aprofundada. E a Carta do Restauro (1972) complementa o conceito de restauro em seu quarto artigo:

Entende-se por salvaguarda qualquer medida de conservação que não implique a intervenção direta sobre a obra; entende-se por restauração qualquer intervenção destinada a manter em funcionamento, a facilitar a leitura e a transmitir integralmente ao futuro as obras e os objetos definidos nos artigos precedentes.

A dificuldade em transpor os conceitos teóricos da preservação para as ações práticas de intervenção em monumentos históricos é real e visível. Os mecanismos legais nem sempre auxiliam esse processo, sendo que, além dos equívocos formais registrados em 
leis e decretos, ainda é notável a interferência política, que, de forma parcial, facilita ou não a aprovação de determinados projetos. Essa interferência passa ao largo das questões técnicas e é orientada por interesses econômicos e políticos, o que afasta totalmente os princípios básicos da motivação que gera a preservação e conservação dos monumentos históricos, ou seja, a valorização da cultura.

E qual é a motivação que leva à preservação de algo? Por que preservar? A preservação é justificada por razões culturais, éticas e científicas. É definida como um ato de cultura e deve ser ditada por aspectos estéticos, históricos, memoriais e simbólicos.

A dualidade entre os princípios teóricos correlatos ao campo do restauro - defendidos pelos técnicos dos órgãos de preservação - e os interesses econômicos - defendidos de forma disfarçada por políticos - não é uma situação encontrada apenas no Brasil. Em conferência(6) recente realizada no edifício Vila Penteado, sede da Pós-Graduação da Faculdade de Arquitetura e Urbanismo da Universidade de São Paulo, a conferencista, Prof. ${ }^{a}$ Dra $^{a}$. Ascensión Hernández Martínez, iniciou sua apresentação afirmando que há hoje, na Espanha, um distanciamento entre a teoria, a legislação e a prática relacionadas ao campo do restauro. Visando exemplificar essa situação, ela apresentou doze casos de intervenções feitas, nos últimos cinco anos, em edifícios e sítios históricos.

A Lei de Patrimônio Histórico Espanhol, de 1985, vincula a restauração de edifícios ao planejamento urbano, estabelece critérios claros de restauração (art. 39.1, "conservação, consolidação e melhora"), proíbe a reconstrução e ressalta que todas as fases históricas do monumento devem ser respeitadas. Entretanto, pelos exemplos apresentados pela Prof. ${ }^{a}$ Ascensión, fica claro que, não raras vezes, a teoria da preservação se distancia das ações práticas de intervenção, sendo que a legislação, apesar de clara, não é cumprida em sua totalidade. Esse fato se justifica pela situação atual do governo central, que não tem autoridade sobre as Comunidades Autônomas, responsáveis pela aprovação dos projetos, e não tem como anular os equívocos aprovados como sendo atos de preservação. Inclusive há hoje uma situação controversa, em que os políticos espanhóis conseguem aprovar obras que não são validadas pelos técnicos do campo do restauro.

Mas e a situação no Brasil? A educação patrimonial historicamente tem se colocado como excelente ferramenta. Quando disponível, traz informações que fazem que os cidadãos 
validem as ações de cultura, fazendo parte do processo de preservação. Entretanto, quando a educação não é estimulada, as ações podem se tornar arbitrárias.

Uma grande ferramenta, para promover a preservação, é operar de forma a fazer que a população se aproprie dos valores correspondentes a cada obra de interesse cultural e torne os monumentos históricos parte de sua própria história. Através da educação patrimonial, a população pode obter a consciência de seu papel na preservação dos monumentos históricos.

Em relação aos teóricos do restauro, mergulhar no campo da prática, enfrentar obras, vivenciando o canteiro de obras, talvez seja o caminho a ser perseguido.

Para os profissionais que viabilizam as ações práticas, é imprescindível conhecer a teoria, inclusive a ponto de formar mão de obra capacitada para o entendimento da relevância do patrimônio arquitetônico e de suas características singulares.

O conhecimento, por parte dos trabalhadores da construção civil, da importância da obra que estão realizando faz que os mesmos se tornem aliados do processo de preservação.

$\mathrm{Na}$ conferência "Tendências tradicionais de construção e conservação arquitetônica: alguns casos de estudo"(7), o Prof. Dr. João Carlos de Oliveira Mascarenhas Mateus comentou sobre as culturas construtivas e o fato de que precisamos compreender 0 estado da nossa cultura construtiva, destacando que a reabilitação, conservação e restauro devem garantir a autenticidade e integridade dessas culturas.

Estudos de caso foram apresentados, visando esclarecer as fases do processo de conservação arquitetônica, em que o projeto deve detalhar cada tema, desde o entorno até a conservação dos materiais, instalações de equipamentos e entendimento arquitetônico.

Além da preocupação de trabalhar os conceitos teóricos no projeto, o Prof. João Carlos afirmou com convicção a necessidade de desenvolver o projeto de preservação detalhadamente, usando da criatividade para trabalhar cada elemento. Entretanto nem o conhecimento teórico, nem o desenvolvimento adequado do projeto serão suficientes para 
o resultado final de excelência da obra, se os serviços executados não forem feitos por pessoas capacitadas. E, nesse ponto, alguns mitos se esclarecem: de fato, o Brasil tem carência de mão de obra especializada, mas essa situação não justifica termos obras de intervenção no patrimônio arquitetônico com qualidade inferior. O Prof. João Carlos informou que em Portugal também há falta de profissionais especializados, mas ele usa o canteiro de obras para trabalhar a qualificação da mão de obra disponível. Inicialmente os funcionários precisam conhecer a história, o significado da obra em questão, e depois os critérios de restauro podem ser transmitidos.

A problemática que envolve as intervenções em edifícios tombados pode ser atenuada com a sistematização da manutenção programada, que também deve ser planejada a partir da reflexão teórica. A questão da manutenção contínua não é algo novo, a Carta de Veneza (1964) já afirma, em seu artigo quarto: "a conservação dos monumentos exige, antes de tudo, manutenção permanente"(8). Entretanto a falta de manutenção é um problema central para a eficácia da preservação de obras relevantes. Os motivos que levam a essa realidade giram em torno da falta de recursos humanos e financeiros, sobretudo nos casos em que o edifício é público. A falta desses recursos está relacionada com a lentidão dos processos e a falha da sistematização das ações projetuais.

Como já comentado, dentro do campo da preservação, a manutenção refere-se às ações cotidianas e periódicas, que têm por objetivo resolver os problemas assim que surgem, e, no caso da manutenção preventiva e programada, as ações de manutenção se antecipam ao aparecimento dos problemas.

A teoria afirma, ainda, que na manutenção é importante trabalhar por analogia, optando por formas e materiais iguais ou semelhantes aos originais, sendo que seu objetivo é contribuir para a conservação do monumento histórico. Entretanto, na prática, é verificável que projetos ou memoriais descritivos que contenham especificações que podem ser substituídas por elementos similares acabam por ter a qualidade da obra comprometida. Isso se deve ao entendimento de que um elemento similar pode ou não ter seu desempenho equivalente, ou seja, quando um elemento é especificado, as questões que deveriam ser destacadas são as relacionadas com a compatibilidade técnica, e não apenas estética. 
Quando a teoria do restauro afirma que, na manutenção ordinária, os elementos podem ser substituídos por outros semelhantes, significa que não apenas as características formais devem ser levadas em conta, os aspectos técnicos devem ser ainda mais relevantes. Afinal, o objetivo é contribuir para a conservação do monumento, e elementos com desempenho técnico inferior irão apresentar vida útil encurtada, propiciando a deterioração do patrimônio arquitetônico, podendo iniciar uma série de patologias construtivas nos sistemas do edifício.

\section{Estudo de caso: instalações elétricas do edifício Vila Penteado}

A transcrição dos conceitos teóricos para as pranchas dos projetos não é tarefa fácil. Desde as informações contidas nos projetos, até a execução da obra, diversos detalhes se perdem, e, com eles, boa parte da qualidade das ações de intervenção.

Isso se deve a diversos fatores, sendo que um deles será aqui destacado e exemplificado: a forma tradicional de apresentação gráfica dos sistemas não contempla as situações de conflito existentes, ou seja, nos desenhos em planta não é possível verificar as interferências tridimensionais, o que leva a uma simplificação das soluções. Assim, no momento de execução das obras, diversos imprevistos surgem, imprevistos esses que poderiam ser identificados nos levantamentos cadastrais e na documentação da obra.

Em relação aos projetos dos sistemas de instalações, a deficiência de entendimento do espaço é ainda maior, já que a rotina atual apresenta um detalhamento extremamente simplificado, ou seja, os sistemas são representados com apenas um traçado em planta e algum desenho esquemático, que, se bem construído, baseia-se em uma perspectiva isométrica. Mas, por ser esquemático, esse desenho em perspectiva não mostra as interferências arquitetônicas dos espaços edificados existentes.

O conteúdo das normas relacionadas às instalações prediais e a formação do projetista de instalações favorecem o desenvolvimento de um projeto racional, objetivo e seguro, o que é bom e almejado, mas torna a visão do projetista limitada, em relação à importância do monumento histórico. Isso se deve ao fato de o projeto tratar apenas do sistema em questão, e acabar por deixar de lado o entendimento global do patrimônio arquitetônico.

Existem hoje diversas ferramentas que possibilitam o levantamento cadastral detalhado, como o uso, por exemplo, de equipamentos escâner a laser 3D. Em recente seminário de 
estudos sobre restauração arquitetônica, intitulado "Técnicas analíticas e de diagnóstico de bens culturais: experiências italianas recentes"(9), o Prof. Dr. Nicola Santopuoli apresentou o papel das ciências na restauração, comentando sobre as técnicas analíticas e de diagnóstico, sobre os objetivos e desdobramentos dos estudos científicos, com destaque para as técnicas de termografia, refletografia e escâner a laser 3D. Entretanto nem sempre é possível contar com esse tipo de equipamento, para o diagnóstico do patrimônio arquitetônico. Caso seja possível usufruir dessa tecnologia, a análise dos resultados permanece indispensável, ou seja, a manipulação dos dados é imprescindível em qualquer levantamento de dados, seja ele através de análise visual, medição manual e registro fotográfico, ou através de espectrofotografia e escâner a laser 3D. O trato com o material resultante deve ser criterioso e possibilitar o registro das questões teóricas. A tecnologia não dispensa a reflexão teórica, afinal, os equipamentos não conseguem manipular as informações para apresentar o entendimento da obra, tão necessário para a tomada de decisões projetuais.

Mais do que obter informações, é necessário articular as mesmas, ou seja, para o cadastro de um edifício a ser preservado, é necessário realizar o levantamento cadastral completo, desenhando todos os elementos com precisão. Entretanto a articulação arquitetônica dos elementos é tão ou ainda mais importante do que a precisão dos detalhes. Inclusive, a produção dos desenhos não deve ser algo automático, eles precisam ser projetados, afinal, até a altura de corte do desenho em planta é relevante, para o cadastro correto do monumento histórico.

Visando exemplificar a questão comentada, a situação existente e os desdobramentos do projeto de instalações elétricas do edifício Vila Penteado fornecem material adequado para análise.

A Vila Penteado, hoje sede do curso de pós-graduação da Faculdade de Arquitetura e Urbanismo da Universidade de São Paulo, foi projetada em 1901 e construída entre os anos de 1902 e 1903. Localiza-se no bairro de Higienópolis, em São Paulo, na Rua Maranhão, 88. O Edifício Vila Penteado apresenta características marcantes e singulares, reveladas em suas fachadas, pinturas murais e detalhes em metal e madeira. Esses e diversos outros elementos transformam o edifício em obra rara, marca de uma época e de conceitos próprios do estilo art nouveau. 
Entretanto as instalações elétricas da Vila Penteado apresentam falhas diversas e insegurança ao uso. O conhecimento da precariedade das instalações, especialmente das elétricas, já é antigo. Em 1998, foi elaborado, pela empresa Ramoska \& Castellani, um projeto de instalações elétricas, buscando adequar as instalações existentes; tal projeto, no entanto, não foi executado. Em 2006, a empresa Bim \& Alves Engenharia de Projetos Ltda. desenvolveu um projeto de reforma geral para as instalações elétricas, também não executado. Entretanto, em 2007, um incidente motivado por um curto-circuito ocorrido em uma caixa de derivação das instalações elétricas, situada no porão, gerou novas discussões sobre a situação das instalações elétricas da Vila Penteado. Naquele momento, a empresa Barreto Engenharia Ltda. foi contratada para elaborar um laudo técnico e, posteriormente, um projeto para reforma parcial das instalações elétricas, visando suprir as necessidades urgentes de reparos, sendo que a reforma geral das instalações elétricas deveria ser feita assim que possível. Em 2008, foram apresentados o projeto básico e o memorial descritivo para reforma parcial das instalações elétricas.

Em março de 2009, foi decidido, em reunião do Grupo Executivo de Gestão dos Espaços Físicos da FAUUSP (GEEF), que o projeto de reforma parcial seria arquivado, e o projeto de reforma geral das instalações elétricas seria orçado:

\footnotetext{
Em relação à questão da situação das instalações elétricas do edifício, decidiu-se por realizar orçamentos para o projeto completo da BIM Engenharia, desenvolvido a partir de diretrizes que se alinham ao projeto de adequação de layout do edifício, já aprovado em Congregação, e, caso necessário, adaptações ou complementações podem ser acordadas quando em contato com as empresas que se propuserem a realizar o orçamento. [...] Sendo assim, o projeto básico realizado pela empresa Barreto Engenharia será arquivado e não será orçado.(10)
}

O projeto de instalações elétricas, desenvolvido em 2006 pela empresa Bim \& Alves Engenharia de Projetos Ltda., partiu do seguinte conceito: as novas instalações devem ser aparentes e destacadas das superfícies existentes (tanto paredes, quanto forros), conforme apresentado no desenho da figura 1. 


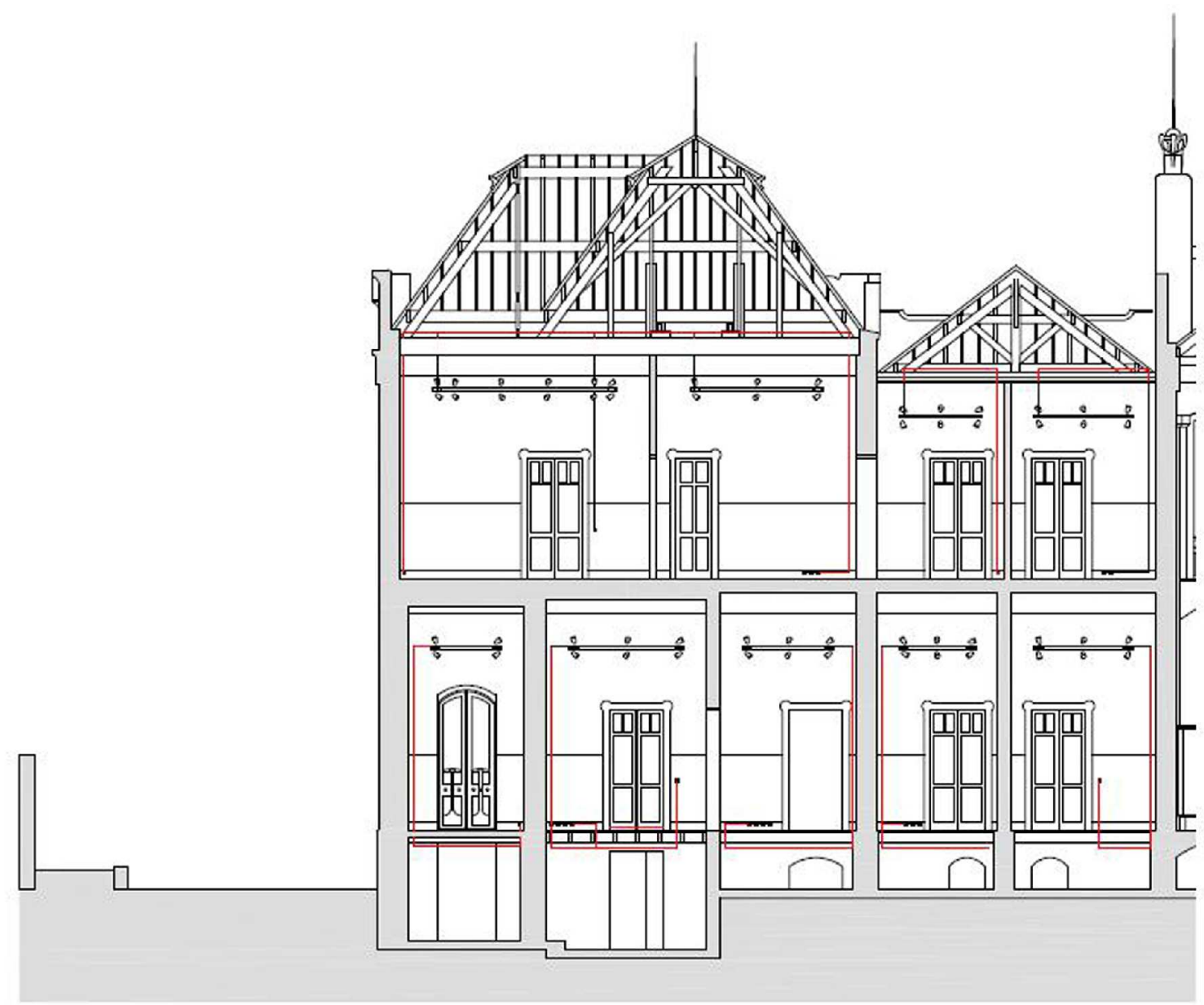

FIGURA 1 - Esquema do Novo Conceito de Iluminação. Fonte: Prancha A-12/12, Universidade de São Paulo, Faculdade de Arquitetura e Urbanismo, Edifício Vila Penteado, Corte 2, junho de 2004, Escala 1:250, Estagiários Pedro Saito, Rafael Ramos e Vanezza Grossman. Desenho apresentado no Relatório de Gestão de 2006 da Vila Penteado.

A iluminação deve ser independente do forro, sendo suspensa por perfilados, e deve ser fixada à estrutura acima do forro, por tirantes ou perfis metálicos. Haverá nova entrada de energia para alimentar o quadro geral, localizado no porão. A partir desse quadro, todos os demais quadros de força e luz serão alimentados. O pavimento térreo deve ser alimentado pelo porão, e o pavimento superior será alimentado através de trajeto encaminhado pelo sótão.

O conceito para a reforma das instalações elétricas foi apresentado no Relatório de Gestão da Vila Penteado de 2006. Nesse mesmo ano, o projeto de instalações elétricas foi concluído pela Empresa Bim \& Alves Engenharia de Projetos Ltda., e foi aprovado junto ao Conpresp (Conselho Municipal de Preservação do Patrimônio Histórico, Cultural e Ambiental da Cidade de São Paulo) e ao Condephaat (Conselho de Defesa do Patrimônio Histórico, Arqueológico, Artístico e Turístico), mediante a apresentação de 
carta de diretrizes(11) e desenhos esquemáticos indicativos, visto que nas pranchas de projeto as diretrizes de preservação não se mostravam de forma clara.

A aprovação no Conpresp foi publicada no Diário Oficial, em 17 de junho de 2010, com o seguinte despacho:

Em sua reunião ordinária de 08 de junho de 2010, o colegiado do Conselho Municipal de Preservação do Patrimônio Histórico, Cultural e Ambiental da Cidade de São Paulo - CONPRESP, com fundamento nos elementos constantes neste processo e considerando o parecer técnico do Departamento do Patrimônio Histórico e do Conselheiro Relator, manifestou-se favorável à reforma das instalações elétricas do imóvel conhecido como Vila Penteado, situado a Rua Maranhão, 88 - Higienópolis. Salientamos que deverá ser atendida toda a legislação edilícia incidente no local, bem como deverão ser consultados, se necessário, os órgãos de Preservação Estadual e Federal.(12)

A carta de diretrizes apresentada contém requisitos que deviam ser atendidos pelo projeto, tais como a distribuição das instalações, feitas por eletrodutos e perfilados aparentes e destacadas das superfícies existentes, permitindo a leitura distinta da arquitetura original e do novo sistema de instalações. A carta traz ainda contribuições visando à organização dos projetos antes do início das contratações para as obras, tais como as constantes no item quatro:

Item 4

A sugestão será incorporada em revisão do projeto a ser feita antes da licitação.

Observação:

Qualquer solução constante do projeto encaminhado e que não esteja de acordo com as descrições acima serão objeto de revisão antes da licitação.(13)

Em função das diretrizes que não estavam totalmente incorporadas ao projeto de instalações elétricas, já aprovado, foi necessário iniciar, em 2011, o levantamento dos pontos conflitantes. Para tanto, a análise visual e fotográfica no local auxiliou esse trabalho, e ainda as consultas aos desenhos existentes, da decoração das paredes internas e das fachadas.

Os eletrodutos e perfilados foram projetados visando seu afastamento das paredes e tetos, o que possibilitaria a visualização das pinturas murais e detalhes art nouveau em 
alto e baixo-relevo, contudo o posicionamento desse sistema interferia sobremaneira na identificação dos elementos decorativos existentes.

Com o levantamento cuidadoso da arquitetura existente, outros detalhes foram observados, tais como o fato de que diversos pontos de luz existentes, que não serão usados para iluminação, poderiam ser aproveitados, em função de sua localização, para auxiliar a instalação de cabos de suporte para os perfilados, ou seja, a fixação dos perfilados deverá privilegiar o uso desses pontos onde já existe furação nos forros existentes, evitando danificá-los ainda mais, lembrando que eles contêm pinturas murais.

Como conclusão desse levantamento feito em 2011, é possível destacar que o projeto de instalações elétricas elaborado em 2006 não prevê o melhor trajeto dos perfilados para iluminação nem para os eletrodutos, prejudicando a leitura adequada da arquitetura da Vila Penteado, portanto os trajetos devem ser ajustados. A falha na escolha dos trajetos deve-se à simplificação das informações, que não consideraram as interferências visíveis nos ambientes.

A verificação pontual dos ambientes originou um novo traçado, que busca a funcionalidade dos espaços aliada à qualidade estética dos tetos e paredes, permitindo uma boa leitura do patrimônio arquitetônico. A observação cuidadosa da arquitetura existente fez que os detalhes arquitetônicos passassem a sugerir os caminhos viáveis para as novas instalações, que não surgiram como interferências.

Em função dessa análise e da verificação de outras interferências existentes, foram traçadas algumas diretrizes para a revisão do projeto de instalações elétricas. Em relação aos perfilados, seu traçado foi alterado em boa parte das salas, respeitando a decoração dos forros, ou seja, a distribuição das luminárias e trajeto dos perfilados devem ser feitos de tal forma, que possibilitem visualizar os forros decorados, tanto os coloridos e desenhados, quanto os que apresentam atualmente apenas variações de relevo. Essa situação pode ser observada na sequência das figuras 2, 3, 4, 5 e 6 . Na figura 2, é apresentado um trecho da planta de forros, que corresponde à Sala de Conferências Prof. Anhaia Mello, conhecida como Sala dos Espelhos, composta por dois ambientes. Na figura 3, é registrada, por meio de fotos, a decoração dos forros da Sala dos Espelhos. Na figura 4, é destacado o trecho do projeto de instalações elétricas de 2006 que 
corresponde à Sala dos Espelhos. Na figura 5, há o levantamento das interferências, com sugestão do novo trajeto para os perfilados, e, por fim, na figura 6, essa mesma área de projeto é apresentada com a revisão feita em 2011. Na figura 6, é possível notar a alteração no traçado dos perfilados, com o objetivo de favorecer a leitura da ornamentação existente nas duas áreas de forro da Sala dos Espelhos, o que aproxima o projeto de suas diretrizes teóricas.

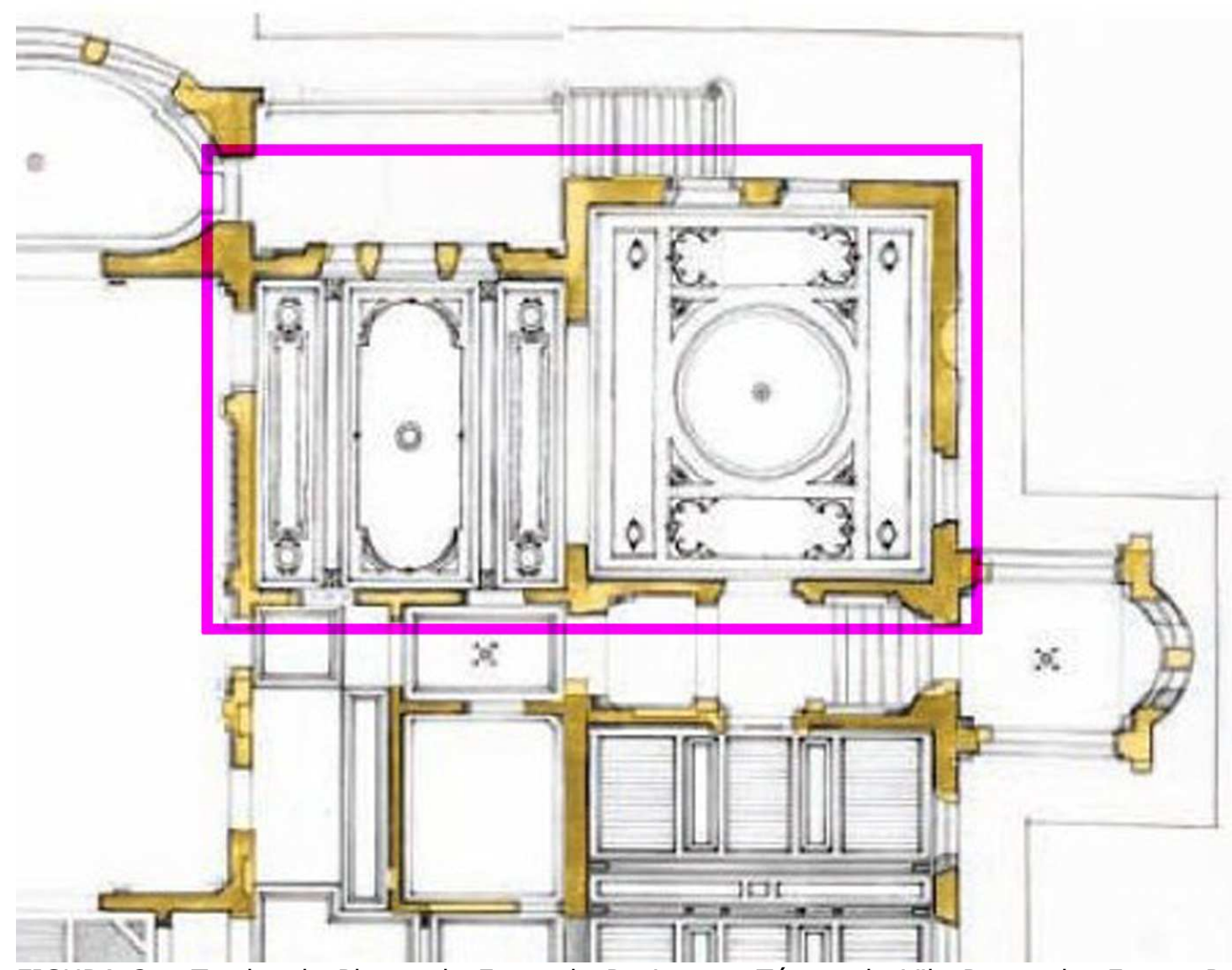

FIGURA 2 - Trecho da Planta de Forro do Pavimento Térreo da Vila Penteado. Fonte: Painel de Inventário Crítico 4/4, $1^{\text {a }}$ Etapa (1990 a 1992): estudo pormenorizado da arquitetura. Mapeamento de Forros. Arquivo CPC USP. Área delimitada pelo retângulo magenta corresponde a Sala dos Espelhos
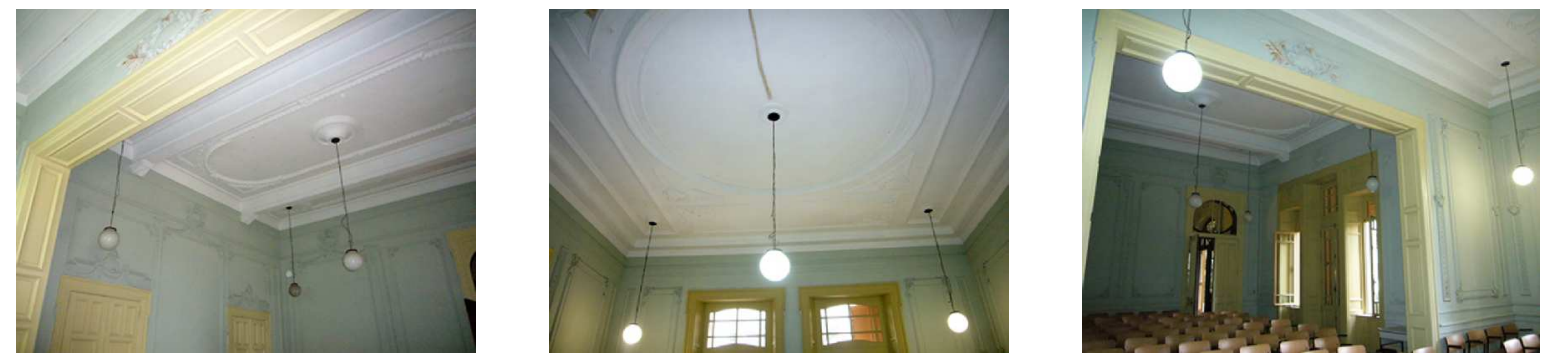

FIGURA 3 - Fotos da decoração dos forros da Sala dos Espelhos da Vila Penteado Fotografia: Foto de Isis Roverso, abril de 2011. 
Tanto nas fotos da figura 3, como no trecho da planta de forros da Vila Penteado, que é apresentada na figura 2, é possível notar que os dois ambientes que compõem a Sala dos Espelhos não são simétricos. Cada ambiente contém um desenho específico de forro, o que faz que o traçado dos perfilados de suporte da nova iluminação também acompanhem esse desenho específico. Entretanto o projeto de instalações elétricas de 2006 prevê um traçado simétrico para os perfilados que sustentarão as novas luminárias. Esse traçado corresponde ao desenho de forro do ambiente menor, mas atrapalha a leitura da gramática da arquitetura do ambiente maior da Sala dos Espelhos.

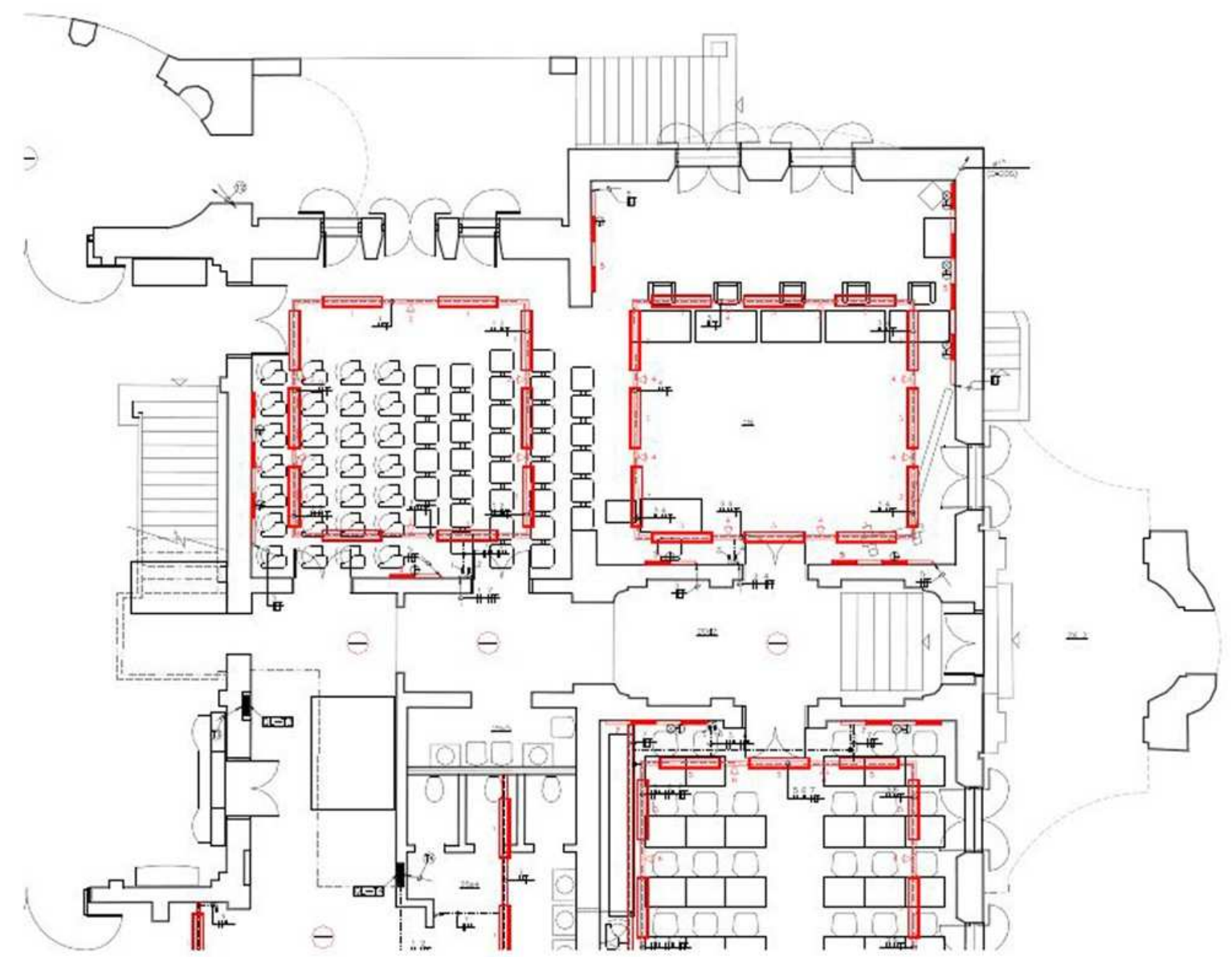

FIGURA 4 - Trecho da Planta do Pavimento Térreo do Edifício Vila Penteado referente ao Projeto de Instalações Elétricas da Empresa Bim \& Alves Engenharia de Projetos Ltda, Folha E-3/9, desenho Eduardo, escala 1:50, nov. 2006.

A figura 5 apresenta o levantamento das interferências, com a sugestão do novo traçado. O novo traçado para os perfilados aparece na cor vermelha, e os pontos indicados pela cor verde representam os locais onde hoje já existem luminárias. Esses pontos marcados na cor verde receberam, preferencialmente, os cabos de sustentação dos perfilados, evitando-se a furação excessiva do forro para passagem dos cabos. 


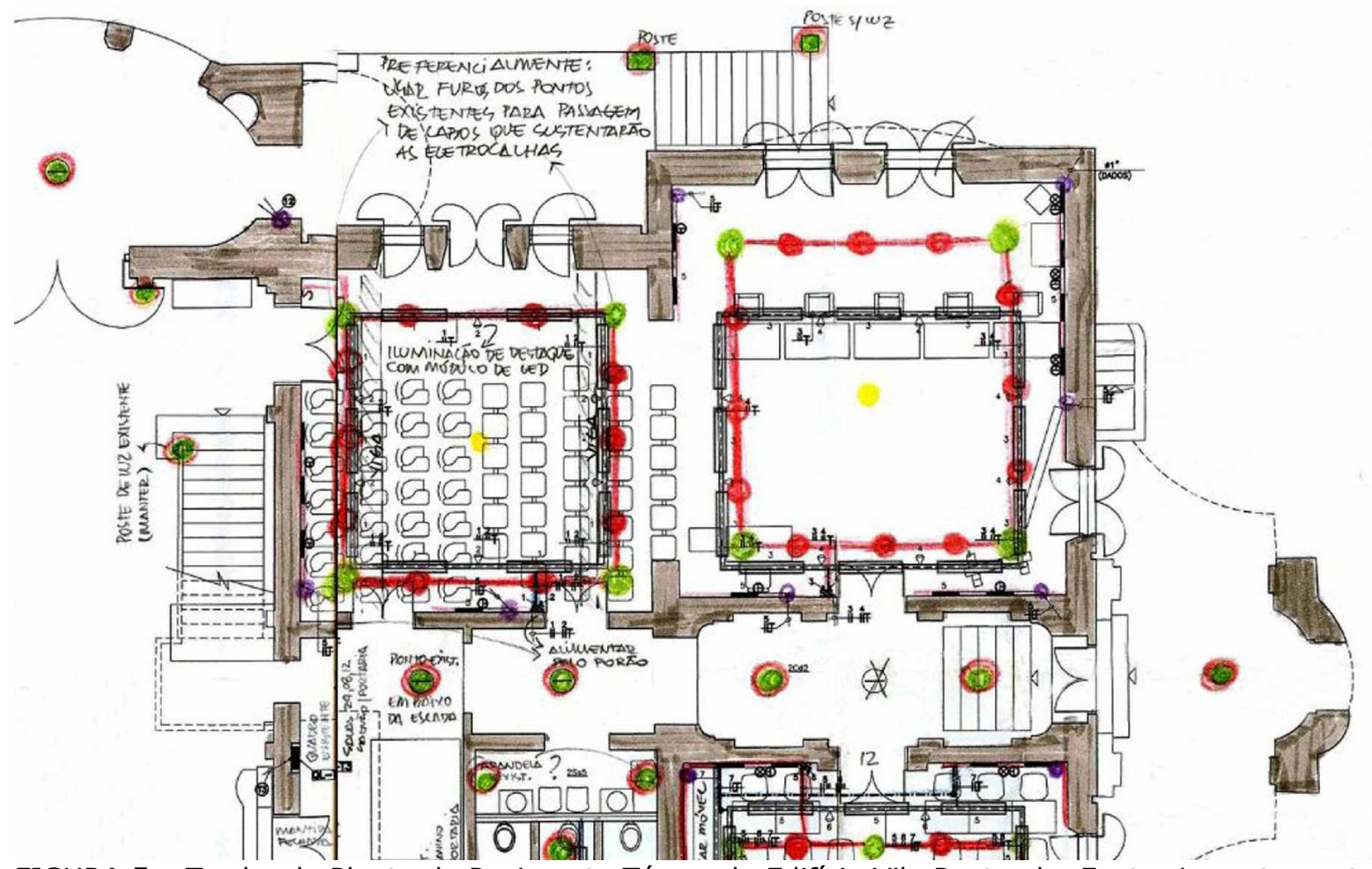

FIGURA 5 - Trecho da Planta do Pavimento Térreo do Edifício Vila Penteado. Fonte: Levantamento de Interferências realizado pela Arqa Isis Roverso em 2011 sobre a base de desenho do Projeto de Instalações Elétricas da Empresa Bim \& Alves Engenharia de Projetos Ltda, 2006.

O trecho do projeto de instalações elétricas que representa a Sala dos Espelhos pode ser visualizado na figura 6 , em que os trajetos dos perfilados foram ajustados, facilitando a visualização da ornamentação dos forros. 


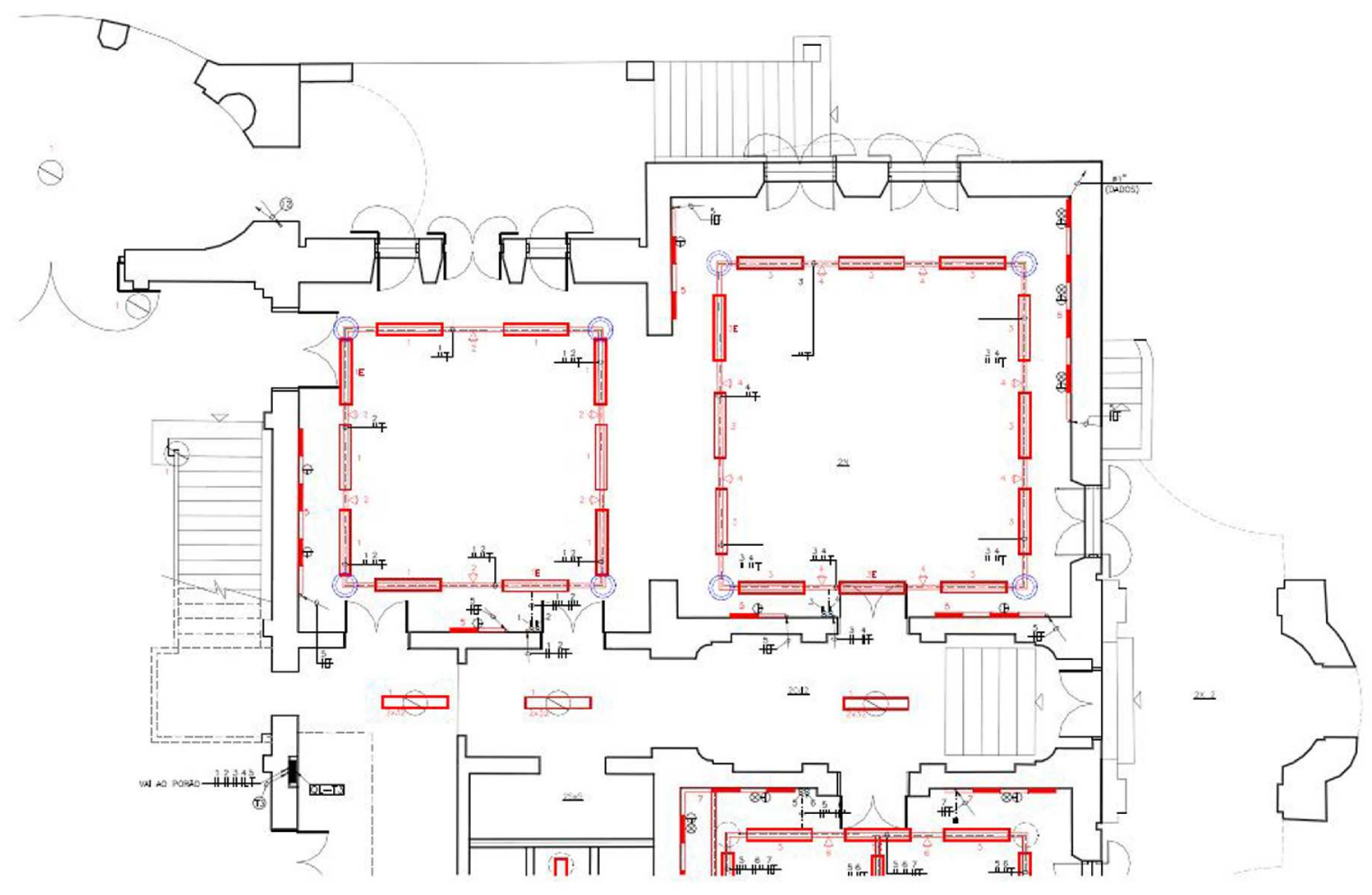

FIGURA 6 - Trecho da Planta do Pavimento Térreo do Edifício Vila Penteado referente ao Projeto de Instalações Elétricas da Empresa Bim \& Alves Engenharia de Projetos Ltda, Folha E-3/9, revisado pelo eng. Marcio Urbani em jun. 2006.

A alteração dos trajetos dos perfilados de sustentação das novas luminárias configura-se como um dos itens pelos quais o projeto de instalações elétricas foi revisado. Há ainda diversos outros elementos que foram ajustados, como a limitação da altura dos perfilados. Os perfilados deverão ficar entre a guarnição superior das janelas e os frisos que emolduram os forros, evitando-se, dessa forma, que gerem excesso de ruído na leitura da arquitetura dos interiores. É importante salientar que essa altura é variável entre salas, visto que os elementos decorativos das janelas e forros também são diferenciados.

Já em relação às réguas para pontos de força, dados e telefonia, a revisão do projeto trata de sua atual falta de continuidade. A extensão dessas réguas é desejável, porque permite eliminar o excesso de descidas de eletrodutos pelas paredes. Essas réguas serão fixadas nas paredes, acima da altura dos rodapés, e terão afastamento propiciado por perfil "U" horizontal de dimensão menor que a régua, ou seja, a régua será sobreposta a um perfil não visível, que a manterá afastada da parede. Inicialmente essas réguas seriam instaladas sobre sapatas fixas nos assoalhos, mas essa alternativa foi descartada porque, além de ser preciso perfurar o piso em madeira, as sapatas metálicas não trariam estabilidade adequada às réguas, e as limpezas de rotina dos pisos seriam prejudicadas. 
Por vezes, o mesmo ambiente receberá mais de um eletroduto vertical. Quando for esse o caso, o projeto deve apresentar os eletrodutos preferencialmente na mesma parede, instalados lado a lado, interferindo dessa forma uma única vez na parede em questão. Quando possível, as réguas das faces opostas de uma mesma parede serão alimentadas com um único eletroduto, ou seja, será feito pequeno furo na parede para passagem da fiação, eliminando, assim, mais uma interferência, com novo eletroduto na face oposta da mesma parede (essa solução só poderá ser usada em casos específicos, onde não cause dano às paredes decoradas).

A iluminação das salas pequenas será revista, especialmente as salas do pavimento superior, onde a alimentação dos pontos de luz é facilitada pelo sótão. Os perfilados serão eliminados, incluindo nova iluminação no ponto de luz existente no forro. A troca da fiação existente é recomendada, e o ponto de luz mantido deverá receber nova lâmpada, a ser especificada.

Salas com mais de uma entrada deverão ter interruptores paralelos, sendo que as portas mantidas permanentemente trancadas não serão consideradas. Os quadros elétricos serão de sobrepor e deverão contar com um dispositivo de proteção contra surtos atmosféricos (DPS).

Algumas áreas, como a do saguão central, terão sua iluminação original mantida, mas será necessário realizar a troca da fiação existente. Os pontos de luz mantidos correspondem às áreas de circulação, especialmente do pavimento superior, e pequenas salas.

A iluminação de destaque prevista no projeto sofrerá alterações. Os pontos direcionados para os forros deverão receber módulos de LEDs. A escolha deu-se em função da disponibilidade atual desse tipo de iluminação, que não projeta calor juntamente com o foco de luz. As demais lâmpadas e luminárias, de uso geral e de tarefa, ainda deverão ser especificadas.

O projeto de instalações elétricas deverá prever ainda carga para a futura implantação do sistema de segurança (iluminação de emergência, bomba para hidrantes, sistema de 
alarme etc.) e das instalações destinadas à acessibilidade do edifício, como a plataforma acessível que auxiliará no trajeto entre o térreo e o pavimento superior da Vila Penteado.

O ideal é já compatibilizar o projeto de instalações elétricas com o projeto de prevenção e combate a incêndios e com os demais projetos de instalações, paisagismo e arquitetura de interiores (alteração no uso e ocupação das áreas existentes). Entretanto tanto o projeto de prevenção e combate a incêndios, como o projeto de instalações hidráulicas e o projeto de acessibilidade ainda não foram desenvolvidos. Mas, em relação à iluminação de emergência, é possível substituir os blocos autônomos por circuitos de emergência, que deverão ser atendidos por uma central com baterias.

É preciso destacar, ainda, algumas alterações pontuais no projeto de instalações elétricas. A primeira delas diz respeito à iluminação externa. Os pontos de luz existentes (postes nas entradas e na área do chafariz) deverão ter seus cabos alimentadores trocados. Novos pontos de luz, além dos poucos existentes, deverão ser previstos, para iluminamento dos trajetos e fachadas. $O$ trajeto da iluminação externa frontal deve prever o desvio em relação à área das raízes das árvores existentes.

Os circuitos das tomadas do pavimento térreo deverão ser revistos, fazendo que todas as tomadas sejam alimentadas pelo porão, sendo que as descidas dos perfilados devem atender apenas aos interruptores. A exceção a essa regra encontra-se nas áreas sem acesso pelo porão, onde as tomadas serão alimentadas pelos perfilados.

As tomadas projetadas na cozinha atual serão substituídas por réguas com pontos de força, conforme padrão do restante do projeto. A iluminação existente na área aberta ao lado da atual secretaria será mantida, e os perfilados projetados serão eliminados.

O projeto de instalações elétricas prevê o uso atual das áreas, com exceção do porão, de que já consta a nova ocupação (há a previsão de serem instalados vestiários e banheiros no subsolo). Quando a proposta de alteração de layout for implantada no edifício, algumas réguas deverão ser realocadas, sendo que a iluminação sofrerá alterações mínimas, visto que a revisão atual contempla o trajeto dos perfilados favorecendo a leitura dos forros decorados existentes, e, dessa forma, eles serão mantidos, mesmo depois da alteração do uso das salas. 
Em função do volume de itens a serem revisados no projeto de instalações elétricas, o engenheiro Marcio Urbani, da Empresa Lumina Comércio e Instalações Elétricas Ltda., foi contratado para realizar a revisão desse projeto, incorporando os itens analisados e ainda desenvolvendo o sistema de proteção contra descargas atmosféricas - SPDA. A partir dos pontos destacados, a revisão do projeto elétrico foi elaborada e entregue pelo engenheiro em junho de 2011.

A respeito da área da Biblioteca, o projeto de instalações elétricas considera que ela deve ser mantida como existente. Sua carga está alocada nos diagramas correspondentes, mas não há informações detalhadas sobre a reforma feita nas instalações em 2000.

Por meio do relato do desenvolvimento do projeto de instalações elétricas para o edifício Vila Penteado, é verificável que a fase inicial de estudos e análise do patrimônio arquitetônico não foi plenamente desenvolvida. Com os levantamentos deficientes, a tomada de decisão acaba sendo conturbada. Os processos são truncados e, mesmo agora, após a revisão geral do projeto definitivo já aprovado nos órgãos de preservação, nem todos os elementos estão definidos, como a questão das lâmpadas e luminárias, e também há áreas onde falta informação sobre as instalações existentes, como é o caso da área da Biblioteca, reformada em 2000. É necessário desenvolver a coleta efetiva e a sistematização das informações, a fim de que as ações de preservação sejam realizadas de forma plena.

Afinal, é importante salientar que o projeto de restauro pressupõe a compreensão integral do monumento histórico. Se não há manutenção preventiva e programada, as ações de intervenção, quando acontecem, acabam tomando grandes proporções, o que, por vezes, mais prejudica do que agrega valor ao patrimônio arquitetônico.

\section{Conclusão}

Resgatando algumas orientações para o trabalho com patrimônio arquitetônico, deixadas pelo Prof. João Carlos na já mencionada conferência "Tendências tradicionais de construção e conservação arquitetônica: alguns casos de estudo", o edifício em questão deve ser estudado de maneira apropriada, com uma lista de "sim" e de "não" orientando e 
limitando as possíveis intervenções. Essa lista deve ser justificada, favorecendo o processo guiado que instruirá futuras intervenções.

Em todo processo de análise e intervenção no patrimônio arquitetônico, é possível cometer erros, entretanto a análise criteriosa diminui muito essa possibilidade, ou seja, tendo em mãos a documentação pormenorizada, as ações frequentes de manutenção podem ser programadas, e os seus limites podem ser estabelecidos. As ações mais invasivas serão dotadas de crítica e caminharão ao largo da possibilidade de se cometer enganos.

O respeito ao patrimônio deve ser ressaltado, afinal, os edifício históricos são verdadeiras caixas de conhecimento, e a motivação da preservação consiste exatamente em manter esses documentos únicos, com suas qualidades próprias, consagradas pela história.

\section{Notas}

(1) O termo "monumento histórico" deve ser esclarecido "[...] por 'monumento histórico', não se deve entender obra grandiosa de valor artístico e histórico excepcional (como foi frequente no século XIX), mas, sim, como propõem variados autores da atualidade, qualquer artefato que adquiriu significação cultural com o tempo, - algo mais relacionado ao seu sentido etimológico e às propostas de Riegl". Kühl (2010, p. 301).

(2) Icomos - International Council on Monuments and Sites (Conselho Internacional de Monumentos e Sítios), órgão criado em 1965 e acolhido como consultor e colaborador pela Organização das Nações Unidas para a Educação, a Ciência e a Cultura (Unesco).

(3) BRASIL. Lei № 11.228, de 25 de junho de 1992. Dispõe sobre as regras gerais e específicas a serem obedecidas no projeto, licenciamento, execução, manutenção e utilização de obras e edificações, dentro dos limites dos imóveis. Revoga a Lei $\mathrm{n}^{\circ}$ 8.266, de 20 de junho de 1975, com as alterações adotadas por leis posteriores, e dá outras providências. Regulamentada pelo DM 32.329/92.

(4) Ibidem.

(5) CARTILHA Patrimônio histórico: como e por que preservar. Coordenação de: Nilson Ghirardello e Beatriz Spisso; colaboradores: Gerson Geraldo Mendes Faria [et. al.]. Bauru, SP: Canal 6, 2008. Divulgação: CREA-SP Conselho Regional de Engenharia, Arquitetura e Agronomia do Estado de São Paulo.

6) A Conferência "Tendências do restauro contemporâneo na Espanha" contou com a presença da conferencista convidada Prof. ${ }^{a}$ Dra . Ascensión Hernández Martínez, do Departamento de História da Arte, Universidade de Zaragoza, na FAU Maranhão, no dia 12 de dezembro de 2011. 
(7) A Conferência "Tendências tradicionais de construção e conservação arquitetônica: alguns casos de estudo" foi proferida pelo Prof. Dr. João Carlos de Oliveira Mascarenhas Mateus, do Centro de Estudos Sociais da Universidade de Coimbra, e ocorreu na FAU Maranhão, no dia 13 de outubro de 2011.

(8) Carta de Veneza, Revista do Patrimônio Histórico e Artístico Nacional, 1987, n. 22, p. 106-107.

(9) O professor da Università degli Studi di Roma "Sapienza", Prof. Dr. Nicola Santopuoli, esteve, nos dias 4 e 5 de novembro de 2010, no programa de pós-graduação da FAUUSP, onde conduziu o seminário intitulado "Técnicas analíticas e de diagnóstico de bens culturais: experiências italianas recentes", realizado na FAU-Maranhão.

(10) Texto extraído da Ata de Reunião no GEEF FAUUSP sobre o Edifício FAU Maranhão, realizada em 2 de março de 2009, com a presença da Arqa Bárbara Ivo, relatora da ata, Prof. ${ }^{a}$ Helena Ayoub e Prof. ${ }^{a}$ Maria Angela Faggin P. Leite.

(11) Carta de diretrizes redigida em 21 de março de 2010, ao Conselho Municipal de Preservação do Patrimônio Histórico Cultural e Ambiental da Cidade de São Paulo - CONPRESP, Att. Sr. Walter Pires, Ref. Proc. 20090.336.619-0, Ofício nº001/CONPRESP/2010.

(12) Situação do Processo 2009.0336619-0. Disponivel em: <http://www3.prodam.sp.gov.br/simproc/navega.asp>. Acesso em: 26 jul. 2010.

(13) Carta de diretrizes redigida em 21 de março de 2010, ao Conselho Municipal de Preservação do Patrimônio Histórico Cultural e Ambiental da Cidade de São Paulo - CONPRESP, Att. Sr. Walter Pires, Ref. Proc. 20090.336.619-0, Ofício nº001/CONPRESP/2010, p.2

\section{Referências Bibliográficas}

IPHAN. Cartas Patrimoniais. Rio de Janeiro, 1999.

Carta de Veneza. Revista do Patrimônio Histórico e Artístico Nacional, 1987, n. 22, p. 106-107.

Carta do Restauro (1972), Disponível em:

<http://portal.iphn.gov.br/portal/montarDetalheConteudo.do?id=12430\&sigla=Legislacao\&retorno=detalheLegislacao > Acesso em: 10 dez. 2010.

KÜHL, Beatriz Mugayar. Preservação do Patrimônio Arquitetônico da Industrialização: Problemas Teóricos de Restauro. Cotia: Ateliê / FAPESP, 2009.

Notas sobre a Carta de Veneza. Anais do Museu Paulista. São Paulo, dez. 2010, v. 18, n. 2, p. 287-320. Disponível em: <http://www.scielo.br/scielo.php?script=sci_arttext\&pid=S0101-47142010000200008\&lng=pt\&nrm=iso> . Acesso em: 13 out. 2011.

. Restauração Hoje: Método, Projeto e Criatividade. São Paulo: Desígnio, 2007, v. 6, p. 19-34. 
TIRELLO, Regina A. Depoimento: Redescobrindo e Restaurando as Pinturas Murais dos Edifícios da USP. In: Comissão de Patrimônio Cultural da USP (Org.

LOURENÇO, Maria Cecília França et al). Bens Imóveis tombados ou em processo de tombamento da USP. São Paulo: EDUSP, IMESP, CPC, 1999, v. 1, p. 202-221.

\section{Créditos}

*Arquiteta e urbanista. Mestre em Tecnologia da Arquitetura pelo Programa de Pós-Graduação da Faculdade de Arquitetura e Urbanismo da Universidade de São Paulo - FAUUSP. isisroverso@usp.br e isis@isisroverso.arq.br

${ }^{* *}$ Engenheira civil. Professora doutora do Departamento de Tecnologia - AUT, da Faculdade de Arquitetura e Urbanismo da Universidade de São Paulo - FAUUSP. ctao@usp.br 